University of Nebraska - Lincoln

DigitalCommons@University of Nebraska - Lincoln

\title{
Anointing Chemicals and Hematophagous Arthropods: Responses by Ticks and Mosquitoes to Citrus (Rutaceae) Peel Exudates and Monoterpene Components
}

\author{
Paul J. Weldon \\ Smithsonian Conservation Biology Institute, weldonp@si.edu \\ John F. Carroll \\ USDA, ARS \\ Matthew H. Kramer \\ USDA, ARS, matt.kramer@ars.usda.gov \\ Robert H. Bedoukian \\ Bedoukian Research, Inc. \\ Russell E. Coleman \\ Walter Reed Army Institute of Research \\ See next page for additional authors \\ Follow this and additional works at: https://digitalcommons.unl.edu/usdaarsfacpub \\ Part of the Agricultural Science Commons
}

Weldon, Paul J.; Carroll, John F.; Kramer, Matthew H.; Bedoukian, Robert H.; Coleman, Russell E.; and Bernier, Ulrich R., "Anointing Chemicals and Hematophagous Arthropods: Responses by Ticks and Mosquitoes to Citrus (Rutaceae) Peel Exudates and Monoterpene Components" (2011). Publications from USDA-ARS / UNL Faculty. 958.

https://digitalcommons.unl.edu/usdaarsfacpub/958

This Article is brought to you for free and open access by the U.S. Department of Agriculture: Agricultural Research Service, Lincoln, Nebraska at DigitalCommons@University of Nebraska - Lincoln. It has been accepted for inclusion in Publications from USDA-ARS / UNL Faculty by an authorized administrator of DigitalCommons@University of Nebraska - Lincoln. 


\section{Authors}

Paul J. Weldon, John F. Carroll, Matthew H. Kramer, Robert H. Bedoukian, Russell E. Coleman, and Ulrich R. Bernier 


\title{
Anointing Chemicals and Hematophagous Arthropods: Responses by Ticks and Mosquitoes to Citrus (Rutaceae) Peel Exudates and Monoterpene Components
}

\author{
Paul J. Weldon • John F. Carroll • Matthew Kramer • \\ Robert H. Bedoukian - Russell E. Coleman • \\ Ulrich R. Bernier
}

Received: 27 September 2010 /Revised: 7 February 2011 /Accepted: 11 February 2011 /Published online: 16 March 2011

(C) Springer Science+Business Media, LLC (outside the USA) 2011

\begin{abstract}
Some birds and mammals roll on or wipe themselves with the fruits or leaves of Citrus spp. or other Rutaceae. These anointing behaviors, as with anointing in general, are thought to function in the topical acquisition of chemicals that deter consumers, including hematophagous arthropods. We measured avoidance and other responses by nymphal lone star ticks (Amblyomma americanum) and
\end{abstract}

\section{P. J. Weldon $(\bowtie)$}

Smithsonian Conservation Biology Institute,

National Zoological Park, 1500 Remount Road,

Front Royal, VA 22630, USA

e-mail: weldonp@si.edu

J. F. Carroll

USDA, ARS, Invasive Insect Biocontrol and Behavior

Laboratory, Beltsville Agricultural Research Center,

Beltsville, MD 20705, USA

\section{Kramer}

USDA, ARS, Biometrical Consulting Service,

Beltsville Agricultural Research Center,

Beltsville, MD 20705, USA

R. H. Bedoukian

Bedoukian Research, Inc.,

21 Finance Drive,

Danbury, CT 06810, USA

\section{R. E. Coleman}

Department of Entomology, Division of Communicable Diseases and Immunology, Walter Reed Army Institute of Research,

Silver Spring, MD 20910-7500, USA

\section{U. R. Bernier}

USDA, ARS, Center for Medical, Agricultural, and Veterinary Entomology,

1600 SW 23rd Drive,

Gainesville, FL 32608, USA adult female yellow fever mosquitoes (Aedes aegypti) to lemon peel exudate and to 24 volatile monoterpenes (racemates and isomers), including hydrocarbons, alcohols, aldehydes, acetates, ketones, and oxides, present in citrus fruits and leaves in order to examine their potential as arthropod deterrents. Ticks allowed to crawl up vertically suspended paper strips onto a chemically treated zone avoided the peel exudate and geraniol, citronellol, citral, carveol, geranyl acetate, $\alpha$-terpineol, citronellyl acetate, and carvone. Ticks confined in chemically treated paper packets subsequently were impaired in climbing and other behaviors following exposure to the peel exudate and, of the compounds tested, most impaired to carveol. Mosquitoes confined in chambers with chemically treated feeding membranes landed and fed less, and flew more, when exposed to the peel exudate than to controls, and when exposed to aldehydes, oxides, or alcohols versus most hydrocarbons or controls. However, attraction by mosquitoes in an olfactometer was not inhibited by either lemon peel exudate or most of the compounds we tested. Our results support the notion that anointing by vertebrates with citrus-derived chemicals deters ticks. We suggest that some topically applied compounds are converted into more potent arthropod deterrents when oxidized on the integument of anointed animals.

Key Words Citrus · Ectoparasites · Ticks · Mosquitoes · Monoterpenes $\cdot$ Anointing $\cdot$ Repellent

\section{Introduction}

Many birds and mammals roll on or wipe themselves with fruits, leaves, or other plant parts (reviewed in Weldon and 
Carroll, 2007). Some animals incorporate aromatic leaves or bark in their nests. Phytochemicals appropriated via these anointing and fumigation behaviors are believed to deter consumers, including nuisance arthropods.

Passerine birds, including grackles (Quiscalus spp.) (Laskey, 1948; Johnson, 1971; Clayton and Vernon, 1993), starlings (Sturnus vulgaris) (Hampe in Stresemann, 1935), and tanagers (e.g., Tachyphonas coronatus and Tangara mexicana) (Sick, 1993), and mammals, including capuchin (Cebus spp.) (Buckley, 1983; Baker, 1996; Leca et al., 2007) and spider monkeys (Ateles geoffroyi) (Richard, 1970), wolves (Canis lupus) (Zimen, 1981), and coatis (Nasua spp.) (C. Cranmore, pers. comm.), anoint with lemons (Citrus limona), limes (Citrus aurantifolia), or other citrus fruits (Rutaceae), applying the peels, pulp, and/ or juice to their integument (Fig. 1). White-faced capuchin monkeys (Cebus capucinus) in Costa Rica fur-rub more frequently with citrus fruits, which are introduced in the Americas, than with native plants (Baker, 1996). Spider monkeys in Panama also fur-rub with the leaves of rutaceous trees (Citrus and Zanthoxylum) (Campbell, 2000).

Humans have long used the Rutaceae as a source of arthropod deterrents. Ancient Europeans placed the fruits and leaves of lemon and other citrus plants among stored garments to deter moths (Arias and Ramón-Laca, 2005). In both the New and Old Worlds, the ethnobotanical uses of the Rutaceae include the topical application of fruit and leaf extracts to repel biting insects (Anaso et al., 1990; Koh and Ong, 1999; Arias and Ramón-Laca, 2005). Sukumar et al. (1991) regard the Rutaceae to be among the most promising of plant families to yield mosquito control agents.
Many volatiles present in citrus tissues possess biocidal and other arthropod-deterrent properties, an observation consistent with the defensive activity hypothesized for these substances in the context of vertebrate anointing. A study of the fumigant activity of 30 citrus peel volatiles against adults of the cowpea weevil (Callosobruchus maculatus), a stored product pest, for example, indicated that the chief component, limonene, and 21 other compounds are insecticidal (Don-Pedro, 1996). An investigation of the contact miticidal activity of 30 monoterpenoids against the two-spotted spider mite (Tetranychus urticae), a plant-infesting pest, found citronellol, carvone, and geraniol among the most effective compounds (Lee et al., 1997). These or other volatile monoterpenes also repel or kill arthropods that molest tetrapods, including ticks (Chungsamarnyart and Jansawan, 1996; Thorsell et al., 2006; Del Fabbro and Nazzi, 2008; Pälsson et al., 2008), mites (Carroll, 1994; Perrucci et al., 1995), lice (Toloza et al., 2006), fleas (Hink et al., 1988), bugs (Safra et al., 2009), and midges (Logan et al., 2009) and other biting flies (e.g., Zaki et al., 2005; Butler, 2007).

Clayton and Vernon (1993) investigated the potential value of grackles' habit of anointing with limes by conducting experiments with the chewing louse, Columbicola columbae, a feather-feeding ectoparasite that impairs host survival and mating success. Lice confined in Petri dishes with lime slices experienced higher mortality than did those confined with water. Lime pulp juice brushed onto lice had little effect, but the peel extract was insecticidal.

We tested nymphs of the lone star tick (Amblyomma americanum), a vector of human monocytic ehrlichiosis in the United States, and adult females of the yellow fever mosquito (Aedes aegypti), a circumtropical vector of yellow

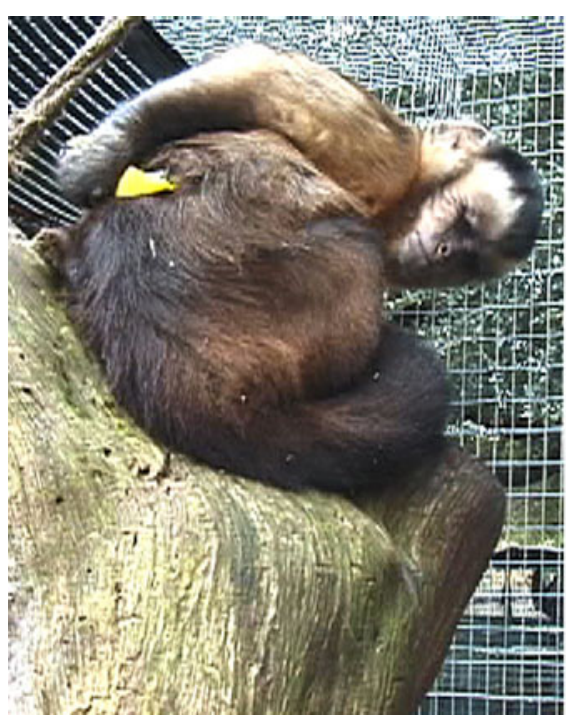

Fig. 1 Convergence in anointing with citrus fruit by New World vertebrates. (left) A tufted capuchin monkey (Cebus apella) rubs a lemon slice against its back. (center) A boat-tailed grackle (Quiscalus
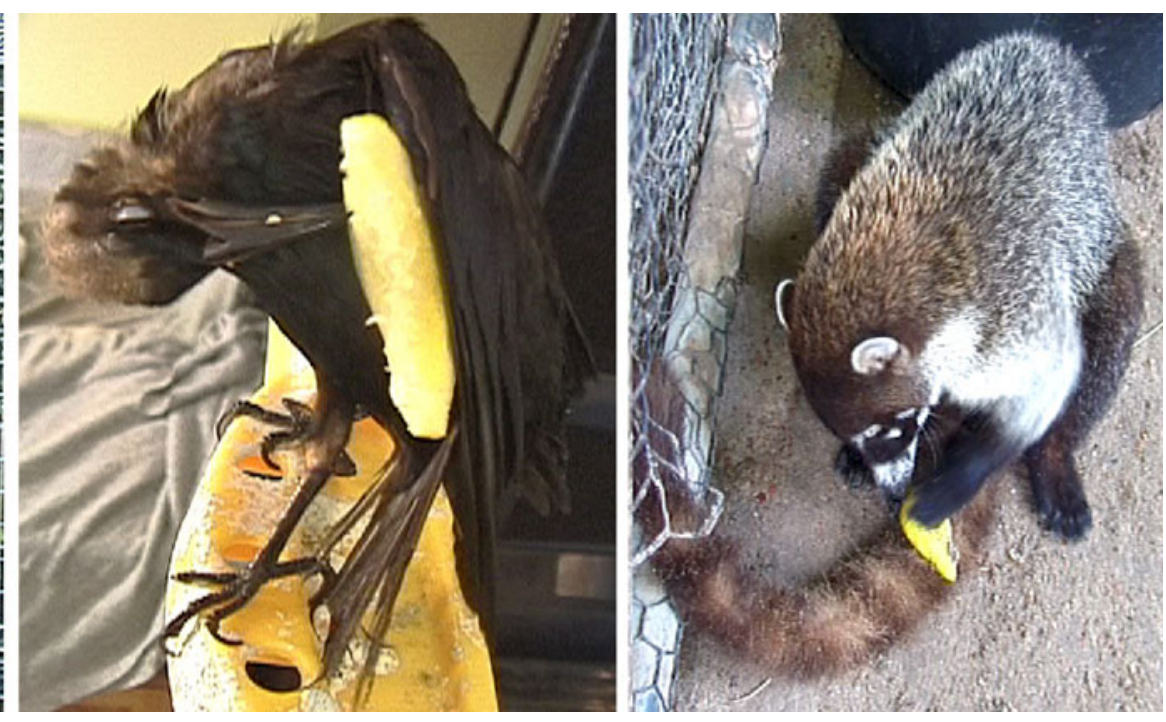

major) rubs a lemon slice against its wing and trunk. (right) A whitenosed coati (Nasua narica) rubs a lemon slice against its tail 
fever and dengue viruses, filariasis, and other diseases, for responses to lemon peel exudate and to the chief volatile monoterpenes reported in citrus fruits and leaves. Bioassays were conducted in order to evaluate these substances as ectoparasite deterrents for animals that anoint with them. Both arthropods were tested with 24 monoterpenes (racemates and isomers), including hydrocarbons, alcohols, aldehydes, acetates, ketones, and oxides.

Tick host-finding behavior ranges from ambushing to hunting, depending upon the species (Waladde and Rice, 1982). When stimulated by chemical or other cues, lone star ticks leave ambush sites and crawl toward stationary or slow-moving hosts. After locating a suitable site on the host, they typically feed for days. Mosquitoes, in contrast, swiftly fly toward and land on hosts, imbibing a blood meal within seconds before departing. We tested these distantly related and behaviorally disparate hematophagous arthropods in assays appropriate to their respective methods of host acquisition.

Arthropods in each assay were tested with fresh (unconcentrated) lemon peel exudate and with individual monoterpenes. Ticks in a repellent experiment were tested for their tendency to avoid a substrate treated with peel exudate or monoterpenes in order to assess how they respond when encountering a scent-laden host. Ticks in a toxicity experiment were tested for their motor performances and host-acquisition responses following confinement with these substances, as might occur when they infest a host's integument where the plumage or pelage traps volatiles. Mosquitoes in a feeding experiment were confined in a module with chemically treated membranes to evaluate their landing, feeding, and flying responses to peel exudate or monoterpenes. Finally, mosquitoes in an olfactometer experiment were presented with an airsteam containing these substances in order to assess their anemotactic responses.

\section{Methods and Materials}

Chemicals Arthropods in each assay were tested with a fresh exudate of an organically grown lemon, obtained by lacerating a $6 \times 6 \mathrm{~cm}$ area of the peel with a razor blade and pressing the exuded fluid against the test medium. Organically grown kale (Brassica oleracea) (also lacerated) and blank (untreated) conditions served as controls.

Ticks and mosquitoes were tested for responses to the following compounds, which typically occur in citrus peels and/or leaves (Dugo et al., 2002; Lota et al., 2002): pcymene, bisabolene, $(+)$-limonene, myrcene, $\alpha$-pinene, $\beta$ pinene, $\gamma$-terpinene, terpinolene, valencene, citral, citronellal, (-)-carveol, citronellol, geraniol, linalool, 4-terpinenol, $\alpha$-terpineol, $(+)$-carvone, $(-)$-carvone, $(+)$ - limonene oxide, (-)-limonene oxide, citronellyl acetate, geranyl acetate, and linalyl acetate. Compounds were dissolved in $0.05 \mathrm{M}$ acetone solutions for feeding membrane tests with mosquitoes and $0.1 \mathrm{M}$ solutions for assays with ticks; acetone alone served as a control. A previous study indicated that the chemical concentrations used in our tests were appropriate to distinguish the effects of different compounds (Kramer et al., 2009); the concentrations of compounds deposited on anointing animals are unknown, but they will vary with the materials used, the duration of anointing, and other factors.

Arthropods Ticks from a colony at the USDA, ARS, Knipling-Bushland U. S. Livestock Insects Laboratory, Kerrville, Texas, were maintained as described by Carroll et al. (2005) and Kramer et al. (2009). At the time of testing, ticks had been in the nymphal stage for 2-6 months.

Mosquitoes for membrane-feeding tests were maintained as described by Weldon et al. (2006). Adult nulliparous female mosquitoes (Liverpool strain), 5-16-d-old, were fed a $10 \%$ sucrose solution presented on cotton pads. The sucrose-soaked pads were replaced with water-moistened pads $48 \mathrm{~h}$ before testing. Mosquitoes (Orlando strain) for the olfactometer test were maintained as described by Kline et al. (2003). Bioassays were conducted up to four times per day $(0700,0900,1100$, and 1300 h). Female mosquitoes, 6-12-d-old, were a fed a sugar solution on cotton pads that were removed $1 \mathrm{~h}$ before testing.

\section{Bioassays with Ticks}

Avoidance Test We investigated repellency by exploiting the tendency of ticks to climb, a key host-seeking behavior, inducing them to crawl onto a chemically treated zone on paper strips (Kramer et al., 2009). Ticks were tested on $1 \times$ $8 \mathrm{~cm}$ strips of recycled bond paper marked at 1-6 cm intervals. In an experiment of the responses of ticks to lemon peel exudate, the paper strips were covered by a piece of tape up to the $2 \mathrm{~cm}$ mark. The lacerated area of a lemon peel was applied by manually pressing it against the strip above the $2 \mathrm{~cm}$ mark. Kale was applied similarly to paper strips; untreated strips served as an additional control.

In an experiment on the repellency of individual compounds, $12 \mu \mathrm{l}$ of each solution or plain acetone were evenly applied by a micropipette to paper strips between the 2 and $6 \mathrm{~cm}$ marks $\left(4 \mathrm{~cm}^{2}\right)$. The strips were air-dried for $1 \mathrm{~min}$, and individual ticks confined in a moated Petri dish were touched with an untreated end of the paper strip and allowed to mount. The paper strip was suspended vertically from a bulldog clip positioned $20 \mathrm{~cm}$ from a light $(275 \mathrm{~W})$ that shone from behind the strip, thus allowing a tick on either side of the paper to be monitored. Ticks were scored for their latencies to cross the $2 \mathrm{~cm}(\mathrm{Q} 2), 3 \mathrm{~cm}(\mathrm{Q} 3)$, and 
$6 \mathrm{~cm}$ marks (Q6) on the strip; the number of times they backcrossed and recrossed the $2 \mathrm{~cm}$ mark $(\mathrm{Qbc})$; and their latencies to drop off the strip (Qld). In our coding system, Q indicates that a variable is quantitative; all variables described above are quantitative (see Kramer et al., 2009 for details). Most quantitative variables are associated with an indicator variable, 1 if the behavior was performed, and 0 otherwise (in our coding system ' $Q$ ' is replaced by ' $\mathrm{I}$ ' to denote these indicator variables). Sessions were concluded when ticks passed the $6 \mathrm{~cm}$ mark, when they dropped from the paper strip or after $10 \mathrm{~min}$ had elapsed.

Righting and Climbing $(R / C)$ Test We investigated toxicity by examining the $\mathrm{R} / \mathrm{C}$ performances of ticks, including their ability to access a human finger, after being confined for $1 \mathrm{~h}$ with lemon peel exudate or test compounds (Carroll et al., 2005). A $5 \times 6 \mathrm{~cm}$ rectangle of filter paper (Whatman No. 4) was marked with a lead pencil $0.5 \mathrm{~cm}$ from the edge. Using a pipettor, $165 \mu \mathrm{l}$ of a test solution or acetone were applied evenly within the $4 \times 5 \mathrm{~cm}$ rectangle bordered by pencil lines. After allowing the paper to air-dry for 10 $15 \mathrm{~min}$, it was folded crosswise, and a bulldog clip was attached to each of two margins. Eight ticks were dumped from a centrifuge tube $(4 \mathrm{~mm}$ inner diam., truncated to $3.5 \mathrm{~cm}$ long, inner side coated with Fluon ${ }^{\mathrm{TM}}$ ) into the cavity formed by folding the paper, and another bulldog clip was attached to the open end of the packet to enclose the ticks. The packets were kept for $1 \mathrm{~h}$ in a glass desiccator containing water below the shelf to maintain humidity $(>95 \%)$.

Immediately after a packet was opened, each nymph was placed on its dorsum on a clay substrate, which supported a vertical filter paper cylinder (diam. $3.2 \mathrm{~cm}$; height $3 \mathrm{~cm}$ ) embedded $3 \mathrm{~mm}$ in the clay and encircling the tick. The latencies for each tick to right itself (Qr) and climb to the top of the cylinder $(\mathrm{Qt})$ were recorded. Test sessions ended after $15 \mathrm{~min}$, whereupon the location of each tick (Qloc) on the bottom (recorded as 0 ), lower side (0.33), upper side $(0.67)$, or on rim or outside the cylinder (1) was noted.

Following these motor performance tests, the ability of ticks to access a host was examined. One of us (J.C.) positioned the tip of his left forefinger 1-2 $\mathrm{mm}$ from the anterior of a (motionless or crawling) tick at $45^{\circ}$ to its right. The tick was allowed $5 \mathrm{sec}$ to climb onto the fingertip. If it failed to do so, the procedure was repeated with the right finger positioned $45^{\circ}$ to the tick's left. If the tick still failed to climb onto the fingertip, the left and right forefingers were again proffered. Each tick had a final opportunity to climb onto the experimenter's left finger, which was placed directly in front of the tick. We scored whether a tick climbed onto a finger (Ih) and the number of trials until a tick climbed onto a finger (Qth).
Morbidity and Mortality Immediately after the $\mathrm{R} / \mathrm{C}$ test, ticks were placed into a plastic vial and returned to their standard maintenance regime. At $24 \mathrm{~h}$ after exposure in the filter paper packet, ticks were observed in a moated Petri dish to assess survivorship. Ticks consistently moving in an uncoordinated manner and a distance of $<5 \mathrm{~mm}$ were considered moribund. Ticks that failed to move after $5 \mathrm{~min}$ in the Petri dish, even when exhaled upon or prodded with forceps, were considered dead. In our analysis, we combined dead and moribund ticks because neither category poses a risk to hosts.

Statistical Methods Data were analyzed as described by Kramer et al. (2009). The basic idea was to use the behavioral differences observed as animals are tested on different compounds to find optimal weightings of these behaviors (i.e., that best discriminate among the compounds) using canonical discriminant analysis. Compounds where animals behave similarly will produce similar composite scores, whereas those compounds that induce different behaviors will produce different scores.

Time variables were square-root transformed. In addition to variables that measure duration or counts of behaviors, indicator variables were created with a value of 1 if the behavior was performed, and 0 if not. This was done so that all variables could be included in the analysis, even if not performed by all individuals. A composite score was created for individual ticks (or, for mosquitoes, a group of five mosquitoes in the chamber, described below). Useful variables to create the score were determined in a stepwise discriminant selection procedure. The composite scores we created used only the first of these canonical discriminant functions, which consisted of the sum of these variables with weights (referred to as 'loadings') from the first axis that best separated the compounds. Because the composite scores for each compound were not normally distributed, we used the non-parametric a posteriori Kruskal-Wallis procedure to determine which compounds differed from the acetone control and from each other. We calculated the median score and 16 and $84 \%$ quantiles for each compound. This calculation gives $68 \%$ percent coverage, so, had the data been normally distributed, these quantiles would be approximately one standard deviation on each side of the mean.

The results of the lemon, kale, and blank tests were included in the data when creating the composite score because we wanted these tests to be on the same scale as that used for the citrus compound scores, but they were analyzed separately for significant differences (i.e., after the composite scores were created, the data were split into two subsets for the Kruskal-Wallis significance tests). The reason for this is that the controls for the two subsets differed; for the lemon exudate, it was kale and blank; for the citrus compounds, it was acetone. 
Two sets of analyses were conducted. One set of tick results measured avoidance, i.e., failure to enter and remain in a chemically treated zone. The other measured toxicosis, as reflected in impaired motor performance/host acquisition. The Pearson correlation between these two sets of results was calculated.

\section{Bioassays with Mosquitoes}

Membrane-Feeding Test We investigated landing and feeding responses of mosquitoes to chemically treated, artificial feeding membranes, as generally described by Weldon et al. (2006). The test apparatus was a two-piece Plexiglas module. The bottom piece was a $40 \times 7 \times 4 \mathrm{~cm}$ hollow platform supporting six circular wells (diam. $3.8 \mathrm{~cm}$, depth $6 \mathrm{~mm})$. Water $\left(40^{\circ} \mathrm{C}\right)$ flowed through the central cavity of the platform. The top module piece consisted of six $4.5 \times$ $4.0 \times 5.0 \mathrm{~cm}$ chambers, each with a sliding floor positioned over a circular opening (diam. $3.5 \mathrm{~cm}$ ).

The wells of the bottom piece were filled with $7 \mathrm{ml}$ of a $10 \%$ sucrose solution containing ATP $(2.9 \mathrm{mg} / \mathrm{ml})$ to which $75 \mu \mathrm{l}$ of green dye were added. In an experiment of the responses of mosquitoes to lemon peel exudate (previously reported in Weldon and Carroll 2007), a lacerated peel was pressed against a nylon-reinforced silicone membrane ( $0.1 \mathrm{~mm}$-thick); kale-treated and blank membranes served as controls. Membranes were placed over the wells. In an experiment with individual compounds, $50 \mu \mathrm{l}$ of a monoterpene solution or acetone were applied to membranes.

For each test session, five mosquitoes were aspirated into each of 2 or 3 chambers (depending upon the experiment) of the top module piece. The sliding floors of the chambers then were opened, allowing mosquitoes access to the membranes. The number of mosquitoes landing on the membranes, and those flying within the apparatus, were recorded each minute for $5 \mathrm{~min}$. After $5 \mathrm{~min}$, any mosquitoes remaining on the membranes were prodded off with a metal wire, and the sliding floor of each chamber was closed. The top piece of the module was placed into a freezer for $20 \mathrm{~min}$. Mosquitoes were removed from the frozen module, crushed on white paper towels, and examined for the presence of green dye, which indicated that they had fed during a test.

Olfactometer Test We investigated the responses by mosquitoes to citrus volatiles when presented concurrently with an artificial attractant. A stock attractant solution was prepared by dissolving $0.6 \mathrm{~g}$ of $\mathrm{L}-(+)$-lactic acid and $100 \mu$ dimethyl disulfide in $250 \mathrm{ml}$ of acetone (Bernier et al., 2007b). Two aliquots of $500 \mu \mathrm{l}$ of this solution were pipetted into two $1.4 \mathrm{ml}$ plastic vial caps $(15 \mathrm{~mm}$ i.d. $\mathrm{x}$ $9.5 \mathrm{~mm}$ height). A $50 \mu \mathrm{l}$ aliquot of each test compound was delivered by pipet into a smaller vial cap $(9 \mathrm{~mm}$ i.d. $\times 9 \mathrm{~mm}$ height, total capacity $400 \mu \mathrm{l})$. Each cap containing the attractant blend was placed on separate aluminum trays $(7 \times 13 \mathrm{~cm})$ constructed to hold the vials. The vial cap containing the test compound was added to one of the trays.

Mosquitoes were tested in a triple-cage dual-port olfactometer to assess the relative attraction or attractioninhibition, i.e., "repellency" (Posey et al., 1998). Each cage of the three stacked cages consists of a single unit in which a trial was conducted. In each trial, mosquitoes could remain in the cage or fly into one of the two ports containing the treatments. The test compounds were examined in a competitive bioassay, where two treatment combinations were compared (attractant blend vs. attractant blend+candidate repellent); a "blank" or "control" conditions were not used in this case.

Air for the olfactometer was drawn from outside the laboratory, and filtered, cooled, heated, and humidified or dehumidified to achieve the desired conditions for air temperature and humidity. For experiments, the air flow was $28 \pm 1 \mathrm{~cm} / \mathrm{sec}$ with a temperature of $27 \pm 1^{\circ} \mathrm{C}$ and $60 \pm$ $5 \% \mathrm{RH}$. Approximately 75 mosquitoes were transferred to each test cage from a trap after preferential selection of host-seeking females by using a hand-draw box. Mosquitoes were loaded and allowed to acclimate in each cage of the olfactometer for 45-60 min prior to each test. During this period, the port doors were opened slightly to allow a low flow of air to pass through the ports and into the cages.

Treatment order, time of day, and ports and cages used were randomized for these trials. A total of six replicate trials was made for each treatment combination, such that each combination order was tested once in each of the two ports for each of the three cages. At the initiation of a trial, the door was opened to allow mosquitoes access to both ports of a cage. Mosquitoes trapped in each of the ports and those remaining in the cage were counted after each 3-min bioassay.

Statistical Methods For the membrane-feeding tests, data were analyzed using the methods described by Kramer et al. (2009). There were three variables collected from each five-mosquito chamber used to create the composite score. The flying counts (variable 1) were summed [total possible was $25=5$ mosquitoes $\times 5$ min (tallied each minute)] and the total count was divided by 25 , with the resulting proportion arcsine transformed. The number of mosquitoes landing on the membrane (variable 2) were handled the same way. The number of mosquitoes landing elsewhere in the module at each minute was not used (to preserve independence, since the sum of the three tallies would always yield 25). The proportion of feeding mosquitoes (variable 3) also was arcsine transformed (6 possible proportions). The resulting composite scores (one score per module unit of 5 mosquitoes) were tested for compound 
differences using the a posteriori Kruskal-Wallis method, and medians and 16 and $84 \%$ quantiles were calculated.

For the olfactometer tests, mosquitoes at the 3-min tally were either at one of the two ports or elsewhere in the cage. Thus, the data are multinomial in nature (counts in three categories). These multinomial counts could be affected by several variables, such as which treatment was present in which port, and environmental factors, such as temperature (some of these are rolled into a proxy "day" effect). Preliminary analysis of the data revealed a "day" effect for the number of mosquitoes that did not enter either port. Much of the variability in the proportions of mosquitoes entering one of two ports, based on the total number released into the olfactometer for that trial, could be removed by using instead a proportion based on only those mosquitoes that entered a port rather the total released; this is the proportion used (on the arcsine transformed scale) in the analysis. There also was a significant overall bias toward one of the ports; this was adjusted statistically by estimating the bias and subtracting its effect. Other potential variables did not appear to affect the proportions of interest. To be consistent with the other analyses, we used the Kruskal-Wallis method for determining differences among compounds, based on adjusted arcsine-transformed proportions, with the denominator of each proportion being the sum of the counts of mosquitoes at the two ports (typically between 50 and 80 ).

\section{Results}

Ticks The loadings of individual tick behaviors used in constructing the composite scores, and the mean separa- tions for avoidance and the $\mathrm{R} / \mathrm{C}$ test data, using all compounds are given in Table 1 .

For the avoidance test, nine behaviors were deemed important for constructing the discriminant function (Table 1); the one dimension used captured $83 \%$ of the explainable variation. The most salient behavior contributing to the composite score was recrossings (Ibc, partial $R^{2}=0.70$ ); the next two were drop-offs (Ild, partial $R^{2}=0.27$ ) and latency to cross the $3 \mathrm{~cm}$ mark $\left(\mathrm{Q} 3\right.$, partial $\left.R^{2}=0.24\right)$. Most compounds could be placed into one of two groups, those with low mean scores that were similar to the acetone control, and those with high scores, e.g., geraniol (Fig. 2). A few compounds had intermediate scores, e.g., citronellal and linalool. The axis appears to order compounds by their repellency, as desired.

For the R/C test, six behaviors were used to construct the discriminant function (Table 1). The two most important behaviors were location at end of the session (Qloc, partial $R^{2}=0.30$ ) and righting ( $\mathrm{Ir}$, partial $R^{2}=0.20$ ). We used only the first dimension for this score, which captured $57 \%$ of the explainable variation (the second axis, which captured about $26 \%$ of the explainable variation, separated carveol from all compounds except $\beta$-pinene, but carveol already is well separated in the first axis) (Fig. 3). The compounds overlap considerably on the first axis, from low scores, such as those for B-pinene and acetone, to those for the most effective compounds, such as geraniol and carveol. Only carveol impaired righting; only one tick righted after exposure to this compound. We interpret this axis to represent the differential effects of the compounds on motor performance.

Most compounds avoided by ticks also had high composite scores on the $\mathrm{R} / \mathrm{C}$ test (indicating impairment),
Table 1 Loadings for tick behaviors used in constructing composite scores for repellent and righting/climbing bioassays. ' $Q$ ' indicates that the variable is quantitative, ' $I$ ' that it is indicator $(0$ or 1$)$

\begin{tabular}{lr}
\hline Variable Repellent Bioassay (Code) & Loading \\
yes/no passed the $2 \mathrm{~cm}$ mark (I2) & -3.616 \\
latency to pass the $2 \mathrm{~cm}$ mark (Q2) & 0.198 \\
yes/no recrossed $2 \mathrm{~cm}$ mark (Ibc) & 2.302 \\
number recrossings of $2 \mathrm{~cm}$ mark (Qbc) & 0.461 \\
yes/no passed the $3 \mathrm{~cm}$ mark (I3) & -1.286 \\
latency to pass the $3 \mathrm{~cm}$ mark (Q3) & 0.128 \\
yes/no dropped off filter paper (Ild) & 2.356 \\
latency to drop off filter paper (Qld) & -0.099 \\
yes/no passed the 6 cm mark (Ib) & -0.654 \\
Variable Righting/Climbing (Code) & 1.161 \\
location (base, upper or lower side, rim) at 15 min (Qloc) & 0.102 \\
yes/no righted itself (Ir) & -0.001 \\
latency to climb to rim (Qt) & 1.029 \\
yes/no climbed to rim (It) & 1.316 \\
yes/no climbed onto fingertip (Ih) & -0.251 \\
number of host acquisition attempts (Qth) & \\
\hline
\end{tabular}




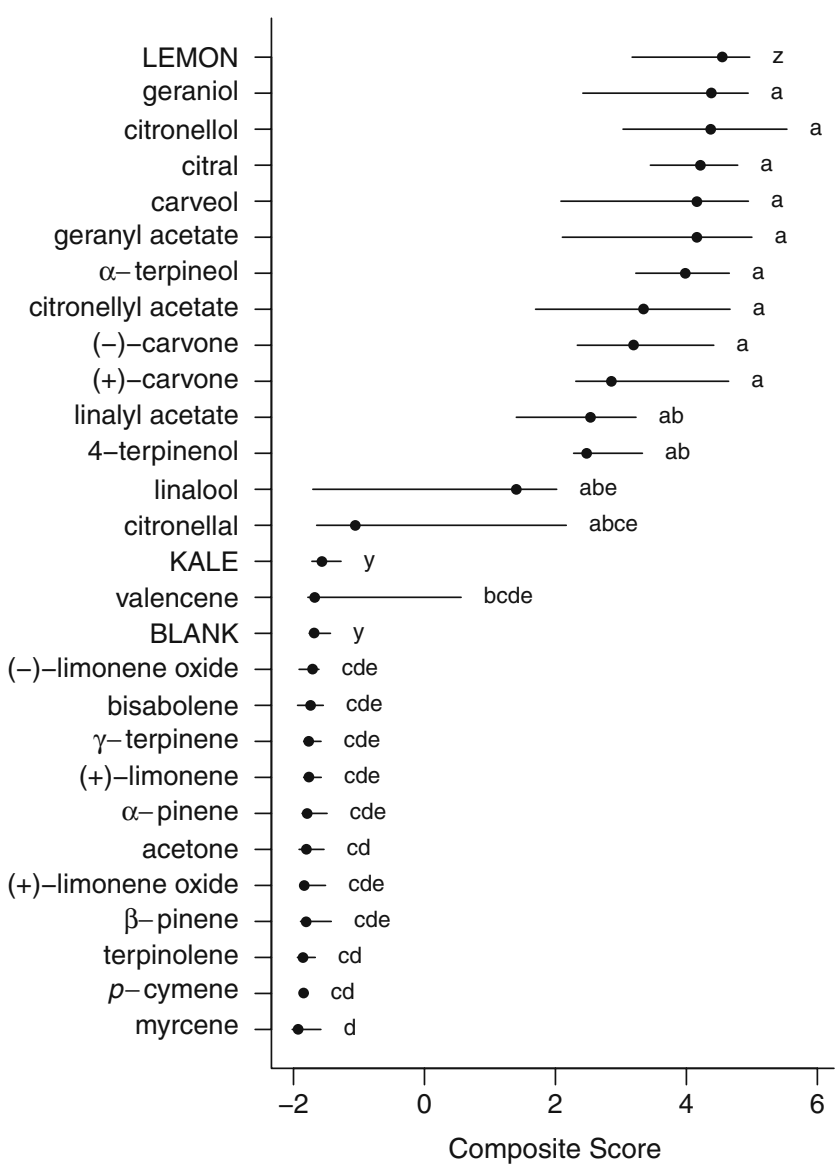

Fig. 2 Rankings of citrus compounds by composite score of five behaviors of lone star ticks to the treated portion of filter paper strips. The median scores and $16 \%$ and $84 \%$ quantiles (horizontal bars, approximately $\pm 1 \mathrm{SD}$ ) are shown. Compounds with the highest scores most repelled ticks. Note lemon and kale are exudates. Compounds with the same letters (following the horizontal bars) do not differ significantly in their effects on tick behavior. There is a separate set of letters ( $\mathrm{y}$ and $\mathrm{z}$ ) for plant exudates and blank

as depicted in the scatter plot in Fig. 4; the correlation coefficient of the two sets of composite scores is $0.72 \quad(P<$ $0.01)$. Linalool, linalyl acetate, and citronellyl acetate were avoided but did not impair behavior. Two compounds, terpinolene and valencene, appeared to impair $\mathrm{R} / \mathrm{C}$ behaviors, but were not avoided. Terpinolene was the only compound for which the impairment of ticks was manifest $24 \mathrm{~h}$ after exposure, with $75 \%$ of subjects moribund and $17 \%$ dead.

Mosquitoes The responses by mosquitoes to nine of the compounds in the membrane-feeding tests were statistically indistinguishable from those to the acetone control. The others had composite scores that differed from the acetone control; 12 compounds/isomers had similar high scores (these are followed by "d" or "de" in Fig. 5). All of the alcohols occurred in this group, as did both isomers of limonene oxide.

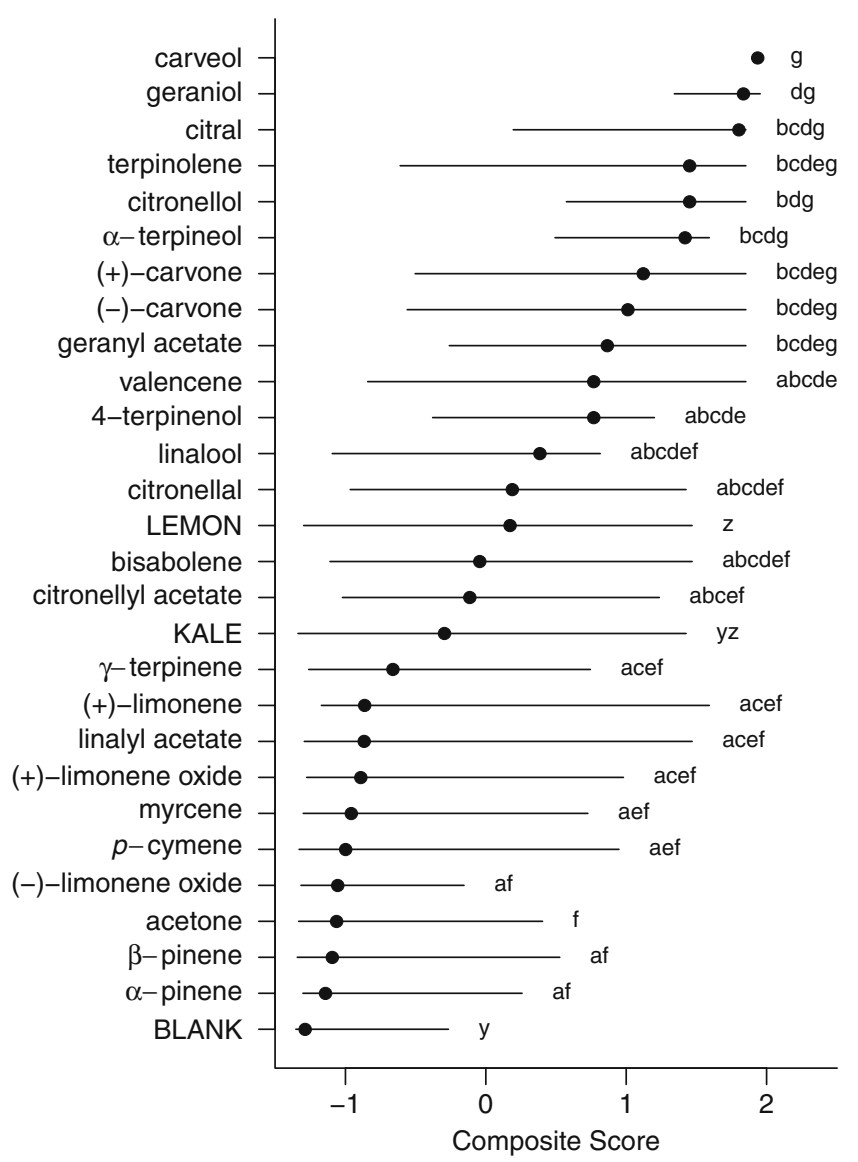

Fig. 3 Rankings of citrus compounds by composite score using righting, climbing, and crawling onto finger by lone star ticks following $1 \mathrm{~h}$ confinement in filter paper packet treated with test solution. The median scores and $16 \%$ and $84 \%$ quantiles (horizontal bars, approximately $\pm 1 \mathrm{SD}$ ) are shown. Compounds with the highest scores most impaired ticks. Note lemon and kale are exudates. Compounds with the same letters (following the horizontal bars) do not differ significantly. There is a separate set of letters ( $y$ and $z$ ) for plant exudates and blank

In the olfactometer test (Fig. 6), responses only to linalool ("repellent") and two compounds, citronellal and $\gamma$-terpinene ("attractants"), differed significantly $(P<0.05)$ from each other. Most of the compounds had at least one trial proportion on each side of the $50 \%$ (inactive) line, and did not differ $(P>0.05)$ from other compounds.

Results from the membrane-feeding test and olfactometer test had essentially no relationship to each other (Fig. 7, Pearson correlation $=-0.219, P=0.28$ ).

\section{Discussion}

Lone star ticks in our study avoided lemon peel exudate and, after confinement with it, exhibited impaired climbing behavior. These responses are consistent with the deterrence of ticks by citrus-derived chemicals applied via anointing, as are our results with a number of compounds we tested. 


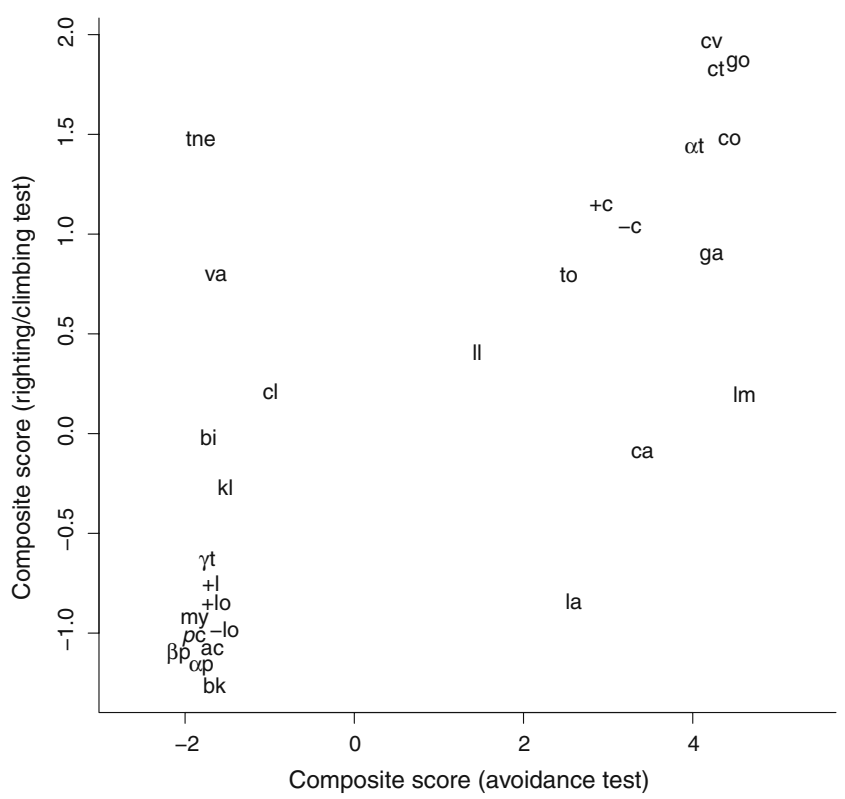

Fig. 4 Scatterplot of composite scores from avoidance (repellent) test and from righting/climbing (motor impairment) test for lone star ticks. Compounds tested were $p$-cymene $(p \mathrm{c})$, bisabolene (bi), $(+)$-limonene $(+1)$, myrcene (my), $\alpha$-pinene $(\alpha \mathrm{p}), \beta$-pinene $(\beta \mathrm{p}), \gamma$-terpinene $(\gamma \mathrm{t})$, terpinolene (tne), valencene (va), citral (ct), citronellal (cl), (-)-carveol (cv), citronellol (co), geraniol (go), linalool (11), 4-terpinenol (to), $\alpha$ terpineol $(\alpha \mathrm{t}),(+)$ - carvone $(+\mathrm{c}),(-)$-carvone $(-\mathrm{c}),(+)$ - limonene oxide $(+\mathrm{lo}),(-)$-limonene oxide $(-\mathrm{lo})$, citronellyl acetate (ca), geranyl acetate (ga), and linalyl acetate (la). Most compounds displayed similar rankings in the two tests, with some exceptions (e.g., terpinolene, "tne", impaired motor performance but was not avoided). Note lemon $(\mathrm{lm})$ and kale $(\mathrm{kl})$ are exudates. Compound codes that overlapped were moved slightly apart for readability

Previous studies on the responses by ectoparasitic acarines to the monoterpenes we examined focus chiefly on mortality. Four monoterpenes tested against the ear mite (Otodectes cynotis) exhibited the following order of miticidal potency: geraniol $>$ limonene $>p$-cymene $>\alpha$ pinene (Traina et al., 2005). A structure-activity study of the contact and fumigation toxicities of 13 monoterpenes against the mange mite (Psoroptes cuniculi) indicated mortalities at or near $100 \%$ for most doses of geraniol, linalool, $\alpha$-terpineol, and 4-terpinenol, but failed to indicate limonene, myrcene, or $\gamma$-terpinene as toxic; linalyl acetate exhibited intermediate toxicity (Perrucci et al., 1995). The observation of Perrucci et al. (1995) that alcohols are the best miticides against mange mites, and that hydrocarbons are least effective, is consistent with our toxicity results with lone star ticks, where carveol was the most toxic compound, and $\alpha$ - and $\beta$-pinene were among the least toxic. Interestingly, a study of the mortality of the southern cattle tick (Rhipicephalus [Boophilus] microplus) to monoterpenes indicated the following order of efficacy: citronellol $>\alpha$-pinene $=\beta$-pinene $>$ linalool (Prates et al., 1998).

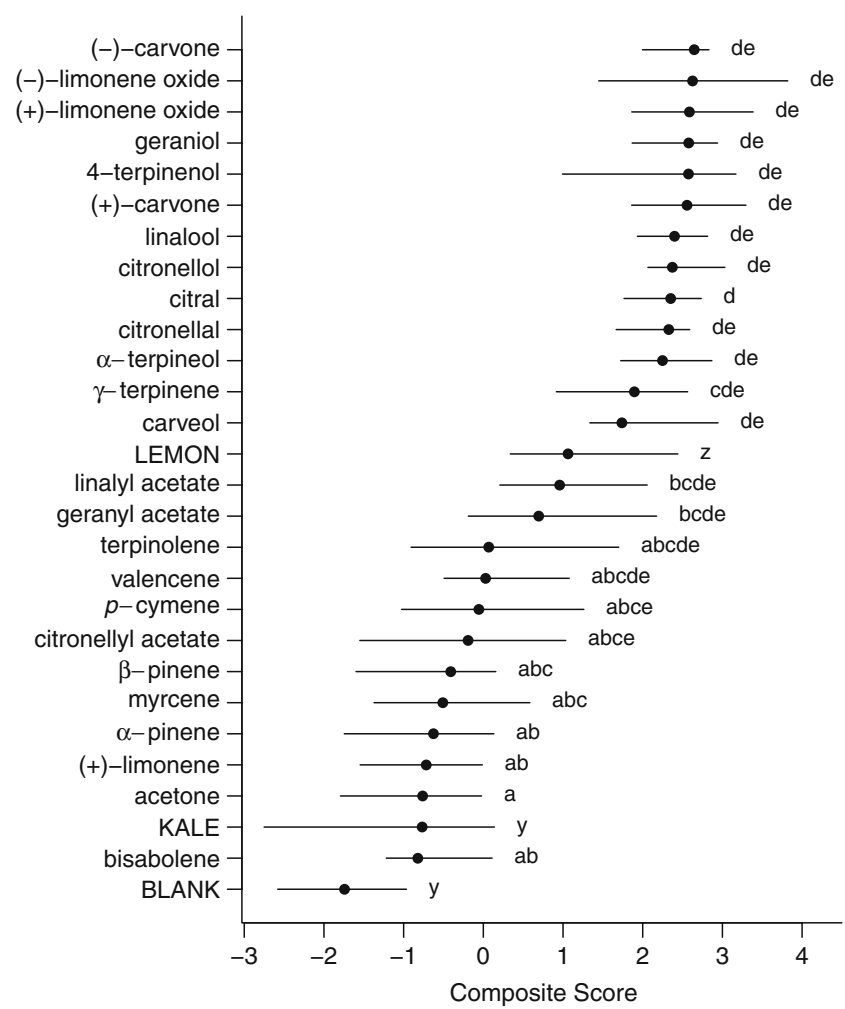

Fig. 5 Rankings of citrus compounds by composite score, using flying, landing, and feeding by yellow fever mosquitoes confined in module containing sucrose solution covered by a membrane treated with test solution. The median scores and $16 \%$ and $84 \%$ quantiles (horizontal bars, approximately $\pm 1 \mathrm{SD}$ ) are shown. Compounds with the highest scores most inhibited landing and feeding, and elicited flying. Note lemon and kale are exudates. Compounds with the same letters (following the horizontal bars) do not differ significantly in their effects on mosquito behavior. There is a separate set of letters (y and $\mathrm{z}$ ) for plant exudates and blank

The monoterpenes we tested with the lone star tick have been tested as repellents with other tick species. Valencene and 4-terpinenol repelled the blacklegged tick (Ixodes scapularis), but not as effectively as did some other terpenes examined (Dietrich et al., 2006). Citronellol, geraniol, $\alpha$-terpinenol, 4-terpinenol, and $\alpha$-pinene repelled nymphs of the sheep tick (Ixodes ricinus) (Thorsell et al., 2006; Tunón et al., 2006; Pälsson et al., 2008), but linalool was ineffective (Tunón et al., 2006; Del Fabbro and Nazzi, 2008). The cattle tick (Rhipicephalus appendiculatus) also was repelled by geraniol and $\alpha$-terpineol, and, to some extent, myrcene (Ndungu et al., 1995; Lwande et al., 1999). In our study, alcohols - geraniol, citronellol, carveol, and $\alpha$ terpineol-were among the most potent repellents (see also Kramer et al., 2009). Citral, geranyl acetate, citronellyl acetate, and carvone also were strongly avoided. On the other hand, hydrocarbons, including myrcene and $p$-cymene, were least repellent. Thus, the compounds that most repel our ticks also are most toxic to them, although exceptions 


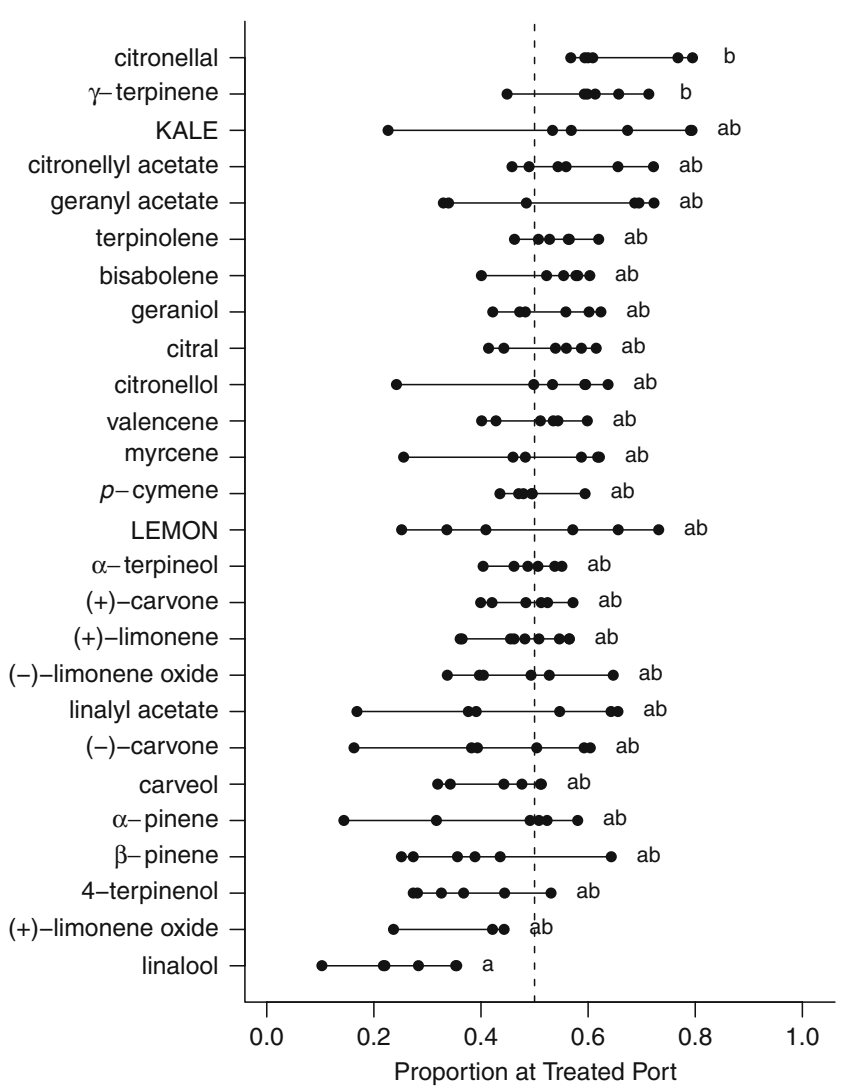

Fig. 6 Proportion of yellow fever mosquitoes at olfactometer port with test compound + attractant blend. Mosquitoes could enter the port with attractant blend only, the port with attractant blend + test compound or remain elsewhere in the olfactometer. The proportions shown are based on only numbers of mosquitoes at the ports at $3 \mathrm{~min}$. Each circle represents the results from one trial. For ease of interpretation, a line connects the results of each of the trials of a compound. Note lemon and kale are exudates. Compounds with the same letters (following the horizontal bars) do not differ significantly in their effects on mosquito behavior. A central dotted line at 0.5 indicates an equal tendency to enter either port. Points further from the line denote greater attractiveness (right) or repellency (left) of the compounds

occur, e.g., terpinolene, which was not avoided but did impair motor performance.

Mosquitoes in our module tests landed and fed least, and flew most, when confined with lemon peel exudate versus kale and blank controls. These results were interpreted to reflect repellence by lemon peel volatiles (Weldon and Carroll, 2007). In our olfactometer, however, lemon peel exudate did not appear to affect mosquito behavior when the insects were presented concurrently with the artificial attractant solution. Moreover, the application of fresh lemon peel exudate to the arm of a human subject (P.J.W.) failed to deter biting by yellow fever mosquitoes. Buckley (1983), who reported that white-faced capuchin monkeys in Honduras fur-rub with oranges and grapefruit, also failed to sustain fewer bites by deer flies (Chrysops sp., Tabanidae) when he applied orange peel exudate to himself.

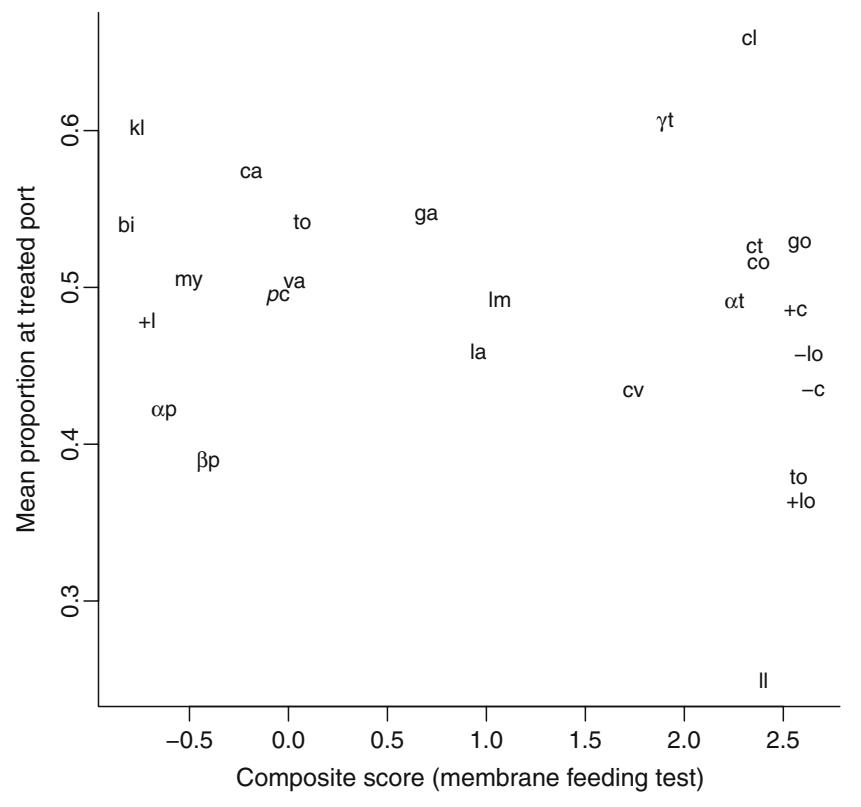

Fig. 7 Scatterplot of composite scores of yellow fever mosquitoes from membrane-feeding test and mean proportion at treatment port from olfactometer test. Results for the two tests appear unrelated. Compounds abbreviated as in Fig. 4. Note lemon and kale are exudates. Compound codes that overlapped were moved slightly apart for readability

Some of the monoterpenes we tested, such as $p$-cymene (Choi et al., 2002; Park et al., 2005; Waliwitiya et al., 2009), carvone (Vartak and Sharma, 1993), citral (Hao et al., 2008), citronellal (Waliwitiya et al., 2009), geraniol (Hao et al., 2008; Müller et al., 2009), terpineol (Traboulsi et al., 2005), and linalool (Choi et al., 2002; Park et al., 2005), have been reported to repel adults of some mosquitoes. Tests of yellow fever mosquitoes often have indicated the greater repellency of alcohols, aldehydes, and related compounds compared to hydrocarbons (Hwang et al., 1985; Zaki et al., 2005), thus supporting Bunker and Hirschfelder's (1925) early observation on the greater overall efficacy of oxygenated compounds as mosquito repellents. Our olfactometer results confirmed Kline et al.'s (2003) result that linalool strongly repels yellow fever mosquitoes, but the olfactometer test did not discriminate among compounds as well as did the module assay; there was no correlation between the results of these two assays.

Higher concentrations of volatiles undoubtedly were presented to mosquitoes in the module than in the olfactometer, both in tests with lemon peel exudate and individual compounds. Some of these volatiles, even those that in low doses attract mosquitoes, may repel them at high concentrations (Bernier et al., 2007a; Butler, 2007). Aside from the likely concentration differences of volatiles in the assay systems, the disparity in the results of our mosquito assays may be due to the kind of data collected and how 
they were analyzed. The olfactometer test scored only one binary behavior variable, and this behavior is related to anemotaxis toward an attractive odor source; the membrane system measured close-range deterrence, which may reflect "repellency." Moreover, the membrane-feeding test scored three behaviors per unit (five mosquitoes), then combined them into a composite score by a weighted summation, with weights to produce scores that separate the compounds; this more sensitive test demonstrated that mosquitoes discriminated among our compounds.

More fundamentally, it is unclear that the module assay applied to mosquitoes distinguishes between compounds that deter landing (as repellents) and those that elicit sustained flight, as by triggering upwind attraction. To clarify this issue, a range of compounds that have well characterized behavioral effects on mosquitoes needs to be tested in assays that distinguish between repellence and flight stimulation.

Some authors focus on limonene in citrus and other plant extracts as a prime deterrent of ticks (Chungsamarnyart and Jansawan, 1996), mosquitoes (Gillij et al., 2008), or arthropods in general (Ibrahim et al., 2001). Limonene in our study did not emerge as a potent deterrent of either ticks or mosquitoes. Nonetheless, limonene in citrus fruits may contribute to deterring some arthropods by virtue of its abundance; it comprises $>90 \%$ of the volatiles of some citrus extracts (Dugo et al., 2002). In addition, limonene applied to the integument of anointed animals may be oxidized on the high surface area of the pelage or plumage into more active agents, such as carveol (Karlberg et al., 1992), which was highly repellent and toxic to our ticks. Similar chemical transformations may occur for other components present in citrus and other anointing materials, thus rendering deterrents from ineffective compounds.

Conjecture on the importance of vertebrate anointing as a defense against hematophagous arthropods should consider the availability of anointing materials in nature. Citrus spp. originated in Southeast Asia and were transported to America by Portuguese and Spanish conquistadores during the early 1500s (Calabrese, 2002). Citrus trees now are widespread in the New World, but they occur chiefly in cultivated regions, thus they may not be encountered routinely by free-ranging animals. For example, whitefaced capuchin monkeys in a region of Honduras devoid of citrus trees were observed to fur-rub only with fruits acquired from humans (Buckley, 1983). The monoterpenes we examined may occur in other materials used for anointing. It is worth noting that some ants, including those used by birds in anointing, such as Acanthomyops spp. and Lasius spp. (Whitaker, 1957), defensively discharge citral, citronellal, citronellol, and related compounds (Blum, 1981).
Falótico et al. (2007) suggested that tufted capuchin monkeys (Cebus apella) anoint with ants in order to acquire formic acid and other topical deterrents of tick nymphs. Similary, DeJoseph et al. (2002) suggested that white-faced capuchin monkeys anoint with plants, including citrus fruits, to combat lice, mites, and ticks. Ticks may be especially vulnerable to topically applied chemicals because they engage in protracted feeding on the integument of hosts (Carroll et al., 2005).

Acknowledgments USDA, ARS, Knipling-Bushland U. S. Livestock Insects Research Laboratory, Kerrville, Texas, provided ticks used in the study. G. Allen, N. Elejalde (Center for Medical and Veterinary Entomology, USDA, ARS, Gainesville, Florida), J. P. Benante, W. Dheranetra, M. Dowler, L. Jones, N. McLean-Cooper, J. R. Murphy, E. Rowton, and J. Williams (Walter Reed Army Institute of Research, Silver Spring, Maryland) assisted with studies of mosquitoes. K. Bagnall (Jungle Friends, Gainesville, Florida), C. F. Cranmore (Tri-Lakes Veterinary Clinic, Mount Pleasant, Texas), and K. Perkowska (Kenner, Louisiana) permitted animals in their care to be photographed. J. Greff (Tonal Vision, LLC, Baltimore, Maryland) prepared Fig. 1. M. P. Fiedler (Gorgas Memorial Library, Walter Reed Army Institute of Research, Silver Spring, Maryland) provided needed references. J. Forbey and D. Strickman commented on the manuscript, and D. Clayton, L. Durden, and J. Weckstein provided valuable discussions. D. Heard and P. and F. Leibe extended numerous courtesies.

\section{References}

Anaso, H. U., Ilouno, L. E, OnUORAH, D., and Umerie, S. C. 1990. Potency of orange peels as a mosquito fumigant. Biol. Wastes 34:83-88.

Arias, B. A., and RAmón-LACA, L. 2005. Pharmacological properties of citrus and their ancient and medieval uses in the Mediterranean region. J. Ethnopharmacol. 97:89-95.

BAKER, M. 1996. Fur rubbing: use of medicinal plants by capuchin monkeys (Cebus capucinus). Am. J. Primatol. 38:263-270.

Bernier, U. R., Kline, D. L., and Posey, K. H. 2007a. Human emanations and related natural compounds that inhibit mosquito host-finding abilities, pp. 77-100, in M. Debboun, S. P. Frances, and D. Strickman (eds.). Insect Repellents: Principles, Methods, and Uses. CRC, Boca Raton.

Bernier, U. R., Kline, D. L., Allan, S. A., and Barnard, D. R. 2007b. Laboratory comparison of Aedes aegypti attraction to human odors and to synthetic human odor compounds and blends. J. Am. Mosq. Control Assoc. 23:288-293.

Blum, M. S. 1981. Chemical Defenses of Arthropods. Academic, New York.

BuCKLEY, J. S. 1983. The Feeding Behavior, Social Behavior, and Ecology of the White-Faced Monkey, Cebus capucinus, at Trujillo, Northern Honduras, Central America. Ph.D. Dissertation, University of Texas, Austin.

Bunker, C. W. O., and Hirschfelder, A. D. 1925. Mosquito repellents. Am. J. Trop. Med. 5:359-383.

BUTLER, J. F. 2007. Use of olfactometers for determining attractants and repellents, pp. 161-194, in M. Debboun, S. P. Frances, and D. Strickman (eds.). Insect Repellents: Principles, Methods, and Uses. CRC, Boca Raton. 
Calabrese, F. 2002. Origin and history, pp. 1-15, in G. Dugo and A. Di Giacomo (eds.). Citrus: The Genus Citrus. Taylor \& Francis, New York.

CAMPBELL, C. J. 2000. Fur rubbing behavior in free-ranging blackhanded spider monkeys (Ateles geoffroyi) in Panama. Am. J. Primatol. 51:205-208.

CARroll, J. F. 1994. Feeding deterrence of northern fowl mites (Acari: Macronyssidae) by some naturally occurring plant substances. Pest. Sci. 41:203-207.

Carroll, J. F., Kramer, M., Weldon, P. J., and Robbins, R. G. 2005. Anointing chemicals and ectoparasites: effects of benzoquinones from millipedes on the lone star tick, Amblyomma americanum. J. Chem. Ecol. 31:63-75.

Chol, W.-S., Park, B.-S., KU, S.-K., and LeE, S.-E. 2002. Repellent activities of essential oils and monoterpenes against Culex pipiens pallens. J. Am. Mosq. Control Assoc. 18:348-351.

ChungSamarnYart, N., and JANSAWAN, W. 1996. Acaricidal activity of peel oil of Citrus spp. on Boophilus microplus. Kasetsart J. (Nat. Sci.) 30:112-117.

Clayton, D. H., and Vernon, J. G. 1993. Common grackle anting with lime fruit and its effect on ectoparasites. Auk 110:951-952.

Dejoseph, M., TAYlor, R. S. L., BAKer, M., and Aregullin, M. 2002. Fur-rubbing behavior of capuchin monkeys. J. Am. Acad. Dermatol. 46:924-925.

Del FABBro, S., and NAZZI, F. 2008. Repellent effect of sweet basil compounds on Ixodes ricinus ticks. Exp. Appl. Acarol. 45:219-228.

Dietrich, G., Dolan, M. C., Peralta-Cruz, J., Schmidt, J., PIESMAN, J., EISEN, R. J., and KARChESY, J. J. 2006. Repellent activity of fractionated compounds from Chamaecyparis nootkatensis essential oil against nymphal Ixodes scapularis (Acari: Ixodidae). J. Med. Entomol. 43:957-961.

Don-PEDRO, K. N. 1996. Investigation of single and joint fumigant insecticidal action of citruspeel oil components. Pest. Sci. 46:79-84.

Dugo, G., Cotroneo, A., Verzera, A., and Bonaccorsi, I. 2002. Composition of the volatile fraction of cold-pressed citrus peel oils, pp. 201-317, in G. Dugo and A. Di Giacomo (eds.). Citrus: The Genus Citrus. Taylor \& Francis, New York.

Falótico, T., Labruna, M. B., Verderane, M. P., De Resende, B. D., IZAR, P., and OTTONI, E. B. 2007. Repellent efficacy of formic acid and the abdominal secretion of carpenter ants (Hymenoptera: Formicidae) against Amblyomma ticks (Acari: Ixodidae). J. Med. Entomol. 44:718-721.

GilliJ, Y. G., Gleiser, R. M., and Zygadlo, J. A. 2008. Mosquito repellent activity of essential oils of aromatic plants growing in Argentina. Bioresour. Technol. 99:2507-2515.

HaO, H., WeI, J., DAI, J., and DU, J. 2008. Host-seeking and bloodfeeding behavior of Aedes albopictus (Diptera: Culicidae) exposed to vapors of geraniol, citral, citronellal, eugenol, or anisaldehyde. J. Med. Entomol. 45:533-539.

HinK, W. F., LiBerati, T. A., and Collart, M. G. 1988. Toxicity of linalool to life stages of the cat flea, Ctenocephalides felis (Siphonaptera: Pulicidae), and its efficacy in carpet and on animals. J. Med. Entomol. 25:1-4.

Hwang, Y.-S., Wu, K.-H., Kumamoto, J., Axelrod, H., and Mulla, M. S. 1985. Isolation and identification of mosquito repellents in Artemisia vulgaris. J. Chem. Ecol. 11:1297-1306.

Ibrahim, M. A., Kainulainen, P., Aflatuni, A., Tillikkala, K., and Holopainen, J. K. 2001. Insecticidal, repellent, antimicrobial activity and phytotoxicity of essential oils: with special reference to limonene and its suitability for control of insect pests. Agr. Food Sci. Finland 10:243-259.

JoHNSON, C. 1971. Grackles (Quiscalus quiscula) use lemon oil for anting. Fla. Nat. 44:123.

Karlberg, A.-T., Magnusson, K., and Nilsson, U. 1992. Air oxidation of $d$-limonene (the citrus solvent) creates potent allergens. Contact Dermat. 26:332-340.
Kline, D. L., Bernier, U. R., Posey, K. H., and Barnard, D. R. 2003. Olfactometric evaluation of spatial repellents for Aedes aegypti. J. Med. Entomol. 40:463-467.

KoH, D., and ONG, C.-N. 1999. Phytophotodermatitis due to the application of Citrus hystrix as a folk remedy. Br. J. Dermatol. 140:737-738.

Kramer, M., Weldon, P. J., and Carroll, J. F. 2009. Composite scores for concurrent behaviours constructed using canonical discriminate analysis. Anim. Behav. 77:763-768.

LASKEY, A. R. 1948. Bronzed grackle anointing plumage with orangeskin. Wilson Bull. 60:244-245.

LeCA, J.-B., Gunst, N., and Petit, O. 2007. Social aspects of furrubbing in Cebus capucinus and C. apella. Int. J. Primatol. 28:801-817.

Lee, S., Tsao, R., Peterson, C., and Coats, J. R. 1997. Insecticidal activity of monoterpenoids to western corn rootworm (Coleoptera: Chrysomelidae), twospotted spider mite (Acari: Tetranychidae), and house fly (Diptera: Muscidae). J. Econ. Entomol. 90:883-892.

Logan, J. G., Seal N. J., CoOK, J. I., StanczyK, N. M., Birkett, M. A., Clark S. J., Gezan, S.A., Wadhams, L. J., Pickett, J. A., and MoRdue (LUNTZ), A. J. 2009. Identification of humanderived volatile chemicals that interfere with attraction of the Scottish biting midge and their potential use as repellents. J. Med. Entomol. 46:208-219

Lota, M. -L., De Rocca Serra, D., Tomi, F., Jacquemond, C., and CASANOVA, J. 2002. Volatile components of peel and leaf oils of lemon and lime species. J. Agric. Food Chem. 50:796-805.

Lwande, W., Ndakala, A. J., Hassanali, A., Moreka, L., Nyandat, E., Ndungu, M., Amiani, H., Gitu, P. M., MalonZA, M. M., and PUNYUA, D. K. 1999. Gynandropsis gynandra essential oil and its constituents as tick (Rhipicephalus appendiculatus) repellents. Phytochemistry 50:401-405.

Müller, G. C., Junnila, A., Butler, J., KravchenKo, V. D., REVAY, E. E., WeISS, R. W., and SchleIN, Y. 2009. Efficacy of the botanical repellents geraniol, linalool, and citronella against mosquitoes. J. Vector Ecol. 34:2-8.

Ndungu, M., Lwande, W., Hassanali, A., MoreKA, L., and ChHABRA, S. C. 1995. Cleome monophylla essential oil and its constituents as tick (Rhipicephalus appendiculatus) and maize weevil (Sitophilus zeamais) repellents. Entomol. Exp. Appl. $76: 217-222$

PÄlsson, K., JAenson, T. G. T., BÆCKSTRÖM, P., and BorGKARLSON, A.-K. 2008. Tick repellent substances in the essential oil of Tanacetum vulgare. J. Med. Entomol. 45:88-93.

PARK, B.-S., CHOI, W.-S., KIM, J.-H., KIM, K.-H., and LEE, S.-E. 2005. Monoterpenes from thyme (Thymus vulgaris) as potential mosquito repellents. J. Am. Mosq. Control Assoc. 21:8083

Perrucci, S., Macchioni, G., Cioni, P. L., Flamini, G., and MORELLI, I. 1995. Structure/activity relationship of some natural monoterpenes as acaricides against Psoroptes cuniculi. J. Nat Prod. 58:1261-1264.

Posey, K. H., Barnard, D. R., and Schreck, C. E. 1998. Triple cage olfactometer for evaluating mosquito (Diptera: Culicidae) attraction responses. J. Med. Entomol. 35:330-334.

Prates, H. T., Leite, R. C., Craveiro, A. A., and Oliveira, A. B. 1998. Identification of some chemical components of the essential oil from molasses grass (Melinis minutiflora Beauv.) and their activity against cattle-tick (Boophilus microplus). J. Braz. Chem. Soc. 9:193-197.

RICHARD, A. 1970. A comparative study of the activity patterns and behavior of Alouatta villosa and Ateles geoffroyi. Folia Primatol. $12: 241-263$.

Safra, V., Zerba E. N., and Alzogaray, R. A. 2009. Fumigant insecticidal activity and repellent effect of five essential oils and 
seven monoterpenes on first-instar nymphs of Rhodnius prolixus. J. Med. Entomol. 46:511-515.

Sick, H. 1993. Birds in Brazil: A Natural History. Princeton University Press, Princeton, New Jersey.

StresemanN, E. 1935. Die Benutzung von Ameisen zur Gefiederpflege. Ornith. Monatsber. 43:134-138.

Sukumar, K., Perich, M. J., and Boobar, L. R. 1991. Botanical derivatives in mosquito control: a review. J. Am. Mosq. Control Assoc. 7:210-217.

Thorsell, W., Mikiver, A., and TunÓN, H. 2006. Repelling properties of some plant materials on the tick Ixodes ricinus L. Phytomedicine 13:132-134.

TolozA, A. C., Zygadlo, J., Cueto, G. M., Biurrun, F., Zerba, E., and PICOLLO, M. I. 2006. Fumigant and repellent properties of essential oils and component compounds against permethrinresistant Pediculus humanus capitis (Anoplura: Pediculidae) from Argentina. J. Med. Entomol. 43:889-895.

Traboulsi, A. F., El-HaJ, S., Tueni, M., TaOubi, K., Nader, N. A., and MraD, A. 2005. Repellency and toxicity of aromatic plant extracts against mosquito Culex pipiens molestus (Diptera: Culicidae). Pest Manag. Sci. 61:597-604.

Traina, O., Cafarchia, C., Capelli, G., Iacobellis, N. S., and OTRANTO, D. 2005. In vitro acaricidal activity of four monoterpenes and solvents against Otodectes cynotis (Acari: Psoroptidae). Exp. Appl. Acarol. 37:141-146.

Tunón, H., Thorsell, W., Mikiver, A., and Malander, I. 2006. Arthropod repellency, especially tick (Ixodes ricinus), exerted by extract from Artemisia abrotanum and essential oil from flowers of Dianthus caryophyllum. Filoterapia 77:257-261.
VARTAK, P. H., and SHARMA, R. N. 1993. Vapour toxicity \& repellence of some essential oils \& terpenoids to adults of Aedes aegypti (L.) (Diptera: Culicidae). Indian J. Med. Res. 97:122127.

WaladDE, S. M., and Rice, M. J. 1982. The sensory basis for tick feeding behaviour, pp. 71-118, in F. D. Obenchain and R. Galun (eds.). Physiology of Ticks. Pergamon, New York.

WAliwitiYA, R., KenNedy, C. J., and LOWENBERGER, C. A. 2009. Larvicidal and oviposition-altering activity of monoterpenoids, trans-anethole and rosemary oil to the yellow fever mosquito Aedes aegypti (Diptera: Culicidae). Pest Manag. Sci. 65:241248.

WELDON, P. J., and CARROLL, J. F. 2007. Vertebrate chemical defense: secreted and topically acquired deterrents of arthropods, pp. 47-75, in M. Debboun, S. P. Frances, and D. Strickman (eds.). Insect Repellents: Principles, Methods, and Uses. CRC, Boca Raton.

Weldon, P. J., Kramer, M., Gordon, S., Spande, T. F., and DAly, J. W. 2006. A common pumiliotoxin from poison frogs exhibits enantioselective toxicity against mosquitoes. Proc. Natl. Acad. Sci., U.S.A. 103:17818-17821.

WHITAKER, L. M. 1957. A resumé of anting, with particular reference to a captive orchard oriole. Wilson Bull. 69:195-262.

ZaKi, Z. M., Ali, N. A. M., AhMad, A. S., Zoll, M. F., Hassan, P. H., JAMIL, I. K. M., and BAKAR, S. A. A. 2005. Four monoterpene compounds: repellency evaluation against Aedes aegypti. Malaysian J. Sci. 24:225-228.

ZIMEN, E. 1981. The Wolf: A Species in Danger. Delacorte, New York. 